\title{
Os Tembé e a relação pesquisador-pesquisado*
}

\author{
Sara Alonso**
}

\section{Introdução}

Neste ARTIGo PRETENDO ANALISAR a relação pesquisador-pesquisado, entendida como uma relação social que se sustenta em critérios culturais para seu controle e grau de legitimidade. Tomando como objeto de análise minha experiência de campo, iniciada em 1989, com os Tembé do Guamá, grupo localizado na Reserva Indígena Alto Rio Guamá (RIARG), no nordeste do Estado de Pará, fronteira com o Estado de Maranhão, tentarei observar alguns dos princípios subjacentes à lógica da relação pesquisador-pesquisado: a "obrigação de dar", "receber" e "retribuir".

Em 1992, num contexto de negociação entre pesquisador-pesquisado, os Tembé do Guamá, classificando-me pela primeira vez como "antropóloga", estabeleceram normas ou "obrigações" que eu deveria cumprir para poder visitar suas aldeias. Entre elas, além de informá-los dos meus planos futuros, eu teria a "obrigação" de contribuir para a "defesa e garantia dos seus direitos" e também para o conhecimento

* Uma primeira versão deste texto foi apresentada no II Encontro de História Oral da Região Norte, em Belém/PA, em maio de 1999.

* Mestre em Antropologia Social pelo Museu Nacional/Universidade Federal do Rio de Janeiro. Pesquisadora Associada ao Departamento de Ciências Humanas do Museu Paraense Emílio Goeldi. 
da "história do grupo". Futuramente, antes de viajar, eu teria a "obrigação" de cientificá-los de minha intenção de retornar à área de Guamá da RIARG ${ }^{1}$. Esta última exigência fundamentava-se na necessidade de controle por parte dos Tembé do ingresso de pessoas de fora na região. Situação semelhante à vivenciada em 1992 repetiu-se três anos depois, quando voltei à Reserva para desenvolver o trabalho dfe campo da dissertação de mestrado. Nessa ocasião, alguns Tembé clarrificaram-me como a "nossa antropóloga".

Também pretendo examinar algumas questões relativas às atribuições culturais dadas à categoria "antropólogo" ou cientista social , principalmente pelas "lideranças" Tembé, com a finalidade de avaliar alguns dos efeitos performativos dos discursos dos cientistas sociais "sobre a realidade social Tembé", os quais, como legítimos agentes produtores e conhecimento, através de seus atos de fala ou de categorização, fazem "sobreviver o que enunciam no próprio ato de o enunciar” (Bourdieu, 1989, p. 116).

Este artigo fundamenta-se nas observações registradas nos diários de campo de 1989 a 1992 e de 1995 a 1998, nos resultados da dissertação de mestrado, defendida em agosto de 1996, no Programa de Pós-Graduação em Antropologia Social no Museu Nacional (Universidade Federal do Rio de Janeiro), e, sobretudo, no desenvolvimento da pesquisa intitulada $A$ relação pesquisador pesquisado: a "obrigação" de "ajuda”, realizada em 1998, no Departamento de Ciências Humanas do Museu Paraense Emílio Goeldi².

\subsection{Considerações sobre o instrumental analítico e as estratégias de pesquisa}

A compreensão da relação pesquisador-pesquisado a partir de critérios "nativos" ou "indígenas" é um procedimento analítico-metodológico

1 A Reserva Indígena Alto Rio Guamá, território de 278.000 hectares, foi oficializada mediante o Decreto 307-21/3/45, assinado pelo Interventor Federal do Pará, Joaquim de Magalhães Cardoso Barata. Os Tembé do Guamá têm uma população aproximada de 370 habitantes, distribuída em 9 aldeias na margem direita do rio Guamá (Alonso, 1996). Na RIARG habitam também os Tembé do Gurupi e Timbira.

2 A pesquisa A relação pesquisador pesquisado: a 'obrigação' de 'ajuda', foi financiada pelo CNPq através do Programa de Incentivo ao Desenvolvimento Científico Regional. 
que tem por finalidade examinar essa relação em "seus próprios termos", tentando compreendê-la a partir da gênese do seu processo de construção e das percepções e representações que o pesquisador e os pesquisados têm da(s) mesma(s) e/ou da(s) realidade(s) social(ais), isto é, evitando sua substancialização ou naturalização.

O uso de categorias "nativas", entendidas como representações a partir das quais os indivíduos de uma determinada coletividade percebem e constróem sua existência social, é um procedimento comum na prática de campo antropológica para compreender uma determinada realidade social. Isto não significa, porém, que tomemos essas categorias integralmente, pois é necessário que as mesmas sejam observadas criticamente a partir do seu poder de manipulação e ocultação (Weber, 1989, p. 22). No momento que se toma como objeto de observação e análise "o indígena", como nos indica Florence Weber, essa denominação se aplica também ao próprio pesquisador, que também pode ser considerado um "nativo". Portanto, o conceito pesquisador-pesquisado não deve ser entendido como uma espécie de unidade, mas como um instrumental operativo destinado a analisar, na sua complexidade, a experiência de campo ou processo interativo entre pesquisador-pesquisado.

Considero importante mencionar alguns dos princípios que subjazem à prática do trabalho de campo pertinentes aos objetivos deste texto. Por exemplo, a idéia de exterioridade ou distanciamento desinteressado é um pressuposto que carece de fundamento se partimos da idéia de que a presença do pesquisador no contexto de campo é, desde o início, resultado de um processo de acertos e negociações, sejam implícitas ou explícitas, inseridas numa determinada lógica de relação social entre o pesquisador e o pesquisado. Essas negociações entre ambas as partes definirão o tipo de inserção do pesquisador no "sistema de classificação do grupo", o próprio lugar que o grupo lhe atribuirá no "espaço social local". A pesquisa, portanto, não é o resultado do "olhar distanciado" e "objetivo" do pesquisador isolado em reflexão no seu gabinete.

Não pretendo refletir aqui sobre a subjetividade ou objetividade das interpretações dos antropólogos (os denominados problemas morais da etnografia), mas sim focalizar a experiência de campo como um evento significativo que cria uma relação social desde os primeiros momentos de contato e nos diferentes contextos de interação, sustentando-se em critérios culturais para seu controle e legitimação. Isto implica considerar, 
de um ponto de vista reflexivo, que minhas ações ou objetivos no campo não têm sempre os resultados esperados, ou podem escapar, nesses momentos, à consciência do pesquisador. Em outros termos, é condição indispensável para uma sociologia reflexiva adotar a "objetivação participante" como procedimento analítico ou maneira de operar do pesquisador. Questão que pressupõe considerar também, como assinalou Bourdieu, o "efeito politico de teoria".

Apoiando-me nas reflexões de Marcel Mauss sobre o "sistema de prestações totais" (Mauss, 1974) e no seu refinamento feito por Bourdieu (1980; 1996), tentei superar também as análises relativas às visões "objetivas" e "interessadas" das relações sociais. Pierre Bourdieu considera que a lógica social das trocas deve ser analisada nas suas condições sociais, mas faz questão de introduzir também na sua análise o tempo entre o dom e o contradom, com o intuito de abordar a incerteza nas ações dos atores desde que se inaugura o círculo de dons, tentando evitar, assim, interpretar a lógica das trocas na sua direcionalidade ou planificação das mesmas como algo objetivo e irreversível, o qual, segundo esses autores, reduziria os atores a meros autômatas que executam regras.

Como estratégia analítica focalizei a avaliação dos contextos de "ruptura" e resultados das negociações realizadas com os Tembé de Guamá em 1992 e 1995, assim como as decorrentes obrigações manifestas nesses dois momentos. Segundo Mauss (1974), as situações de ruptura (ou mudança) permitem que os dons e contradons das relaçôes sociais, aparentemente gratuitos e "desinteressados", expressem sua obrigatoriedade. São momentos nos quais os diferentes agentes revelam com maior clareza o que está em jogo na relação e, consequentemente, os próprios critérios culturais de legitimidade que tais agentes, consciente ou inconscientemente, contribuíram para criar e legitimar.

As mudanças na política indigenista a partir dos anos 1990, concretamente as ocorridas na Administração Regional da Fundação Nacional do Índio (ADR/FUNAI) em Belém, quando Frederico Miranda

3 Para uma melhor compreensão do significado da sociologia reflexiva e do conceito objetivação participante ver "La prática de la sociologia reflexiva (Seminari de París)" (Bourdieu \& Vacquant, 1994, p. 189-229).

4 Segundo Bourdieu, o efeito de teoria é o efeito "propriamente político que consiste em mostrar (theorien) uma 'realidade' que não existe completamente até não ser conhecida e reconhecida" (Bourdieu, 1994, p. 23). 
assumiu o cargo de administrador, favoreceram as condições para que os Tembé se manifestassem e se reconhecessem socialmente, durante o período denominado por eles de "Reorganização-Revolução", como "grupo autenticamente Tembé", possibilitando também a inclusão de novos elementos na relação pesquisador-pesquisado.

As obrigações que os Tembé do Guamá me exigiram em outubro de 1992, como aquelas "impostas" em 1995, estão estreitamente vinculadas, ao mesmo tempo, a esse contexto de "mudança" e às expectativas criadas durante o processo interativo entre pesquisador-pesquisado - ou entre os dons e contradons, naturalizados ou implícitos - que se inauguram ao iniciar a relação, segundo posições diferenciadas atribuídas pelas classificações ou critérios culturais nelas inseridos.

Nesse sentido quero enfatizar que as demandas e comportamentos da relação pesquisador-pesquisado estruturam princípios éticos (ou morais) que fundamentam a regulação e legitimação da relação e suas correspondentes prestações e contraprestações, como uma relação de "longa duração", sendo a categoria "ajuda" a base cultural deste código. Os critérios atribuídos a essa categoria podem variar, segundo contextos ou situações, assim como também suas implicações para a relação, mas a base dos seus fundamentos éticos não parecem ter modificações aparentes.

As "negociações" realizadas em 1992 e 1995, além de contribuírem para forjar novos desafios na minha relação com os Tembé, serviram também para que a suposta lógica da simetria e reciprocidade (ou lógica da generosidade das trocas) da relação mantida entre pesquisadorpesquisado se mostrasse como uma relação desigual de dominação entre "dominantes" e "dominados". Por exemplo, a demanda de "ajuda feita ao antropólogo" (seja para defender os direitos ou como produtora de conhecimento sobre sua história), implica numa relação de dominação, assim como a "obrigação de ajudar como dever moral de cidadão" coloca socialmente os pesquisadores numa posição de dominantes.

A compreensão dessa "relação assimétrica" entre o pesquisador e o pesquisado requer uma avaliação no contexto das relações estabelecidas no "campo de ação indigenista" . Esse campo envolve a ação

5 Utilizo o conceito de "campo de ação indigenista" para me referir ao processo que se desencadeia na RIARG a partir da institucionalização da ação indigenista 
político-administrativa do órgão indigenista e o grupo Tembé num espaço social onde os agentes, com posições e localizações diferenciadas, tentam por meio de um trabalho político, fazer valer sua condição e reconhecimento social. Isto supõe um jogo de alianças e negociações nas quais o pesquisador, a partir do momento em que se introduz nesse espaço, passa, direta ou indiretamente, a ser parte das relações de poder que então se criam ou se manifestam. Assim, ganhando ou não boa reputação, segundo posições e classificações atribuídas no "campo de ação indigenista", o reconhecimento do pesquisador é inquestionável a partir do momento em que estabelece os primeiros contatos, ou inaugura o processo dos intercâmbios.

Para tentar compreender as bases de legitimidade dos vínculos criados na relação pesquisador-pesquisado é necessário também observar a categoria antropólogo dentro da "realidade social" do "Estado-Nação Brasileiro". Um dos aspetos que mais nos chama a atenção dos contextos de negociação com os Tembé é a representação da categoria "antropólogo" feita por alguns membros do grupo, que parece estruturar determinados critérios culturais, muito similares às interpretações de senso comum feitas no seio da academia e/ou por parte de outros setores da "sociedade brasileira”. Interpretações que implicam posições e classificações as quais, consciente ou inconscientemente, o antropólogo reconhece e acredita quando aceita o desafio de pesquisar com índios e passa a formar parte constitutiva das "lutas de classificação" (Bourdieu, 1989; 1992).

$\mathrm{Na}$ tentativa de poder contribuir para essas reflexões, optei pelo desafio de abordar as "obrigações" e/ou demandas de "ajuda ao pesquisador", construindo da própria experiência de pesquisa com os Tembé um objeto de investigação, que no limite refere-se a uma tentativa de refletir a respeito do fenômeno que emerge, no senso comum da academia, em torno à "oposição" entre as ações aparentemente científicas do antropólogo e aquelas adjetivadas como políticas. Penso que essa "oposição" vincula-se à participação dos antropólogos na construção

entre os Tembé iniciada em 1945, criando um tipo de relação e interdependência assimétrica entre índios e agentes do órgão, processada em termos de uma linguagem cultural com princípios implícitos de simetria e reciprocidade para sua legitimação, os quais se expressam no caráter "paternalista", ou ideal "humanista" e "fraternal" da ação indigenista. Ver Oliveira Filho (1988); e Alonso (1996), especialmente os capítulos I e II. 
do "Estado-Nação" e na "ideologia da nacionalidade", bem como aos efeitos que tem sua prática sobre as interpretações que as "pessoas comuns" fazem sobre a "realidade social brasileira", cuja compreensão exigiria ir além dos limites deste artigo, pois obrigaria a examinar o processo de construção e institucionalização das ciências sociais no Brasil e o próprio processo de institucionalização da ação do Estado ou política(s) indigenista(s). Ambos os processos dizem respeito à "naturalização" dos critérios de legitimidade da categoria antropólogo, ou seja, pela atribuição e reconhecimento que o antropólogo tem dentro da divisão do trabalho intelectual como agente legítimo para produzir e falar sobre os índios.

Sou consciente dos riscos ou desafios que estão implícitos no trabalho, tanto pelo esforço de refletir sobre as formas de compreender e perceber a "realidade social" que tem o pesquisador, como porque as representações que o pesquisado elabora sobre o pesquisado estão em estreita conexão com critérios que estruturam as do pesquisador. Em outros termos, penso que ambos os conjuntos de representações são parte e resultado do próprio processo de construção da relação pesquisador-pesquisado, dentro do contexto da "realidade social brasileira".

Este trabalho, portanto, menos que apresentar conclusões, pretende colocar e sugerir questões, compreendidas como uma "pequena semente" na trilha de futuras coletas dentro dos estudos interessados em compreender as realidades sociais, concretamente dos trabalhos que nos últimos anos vêm se desenvolvendo no Brasil a respeito das conexões entre as categorias analíticas do cientista e as do senso comum, ou sobre os efeitos que as categorias e o referencial teórico dos cientistas sociais têm sobre a "realidade social", tal como no presente trabalho, as questões relativas às práticas do antropólogo e seu efeito "performático" sobre a "realidade social Tembé".

\section{Breve contextualização da escolha do referencial empírico e primeiros contatos com os Tembé.}

Em 1988, eu e duas colegas antropólogas recém-formadas na Universidade de Barcelona, elaboramos um projeto de pesquisa intitulado Los Tembé: Articulación Interétnica e Identidad Étnica. A escolha do 
grupo Tembé, como referencial empírico da pesquisa sobre "contatos interétnicos", estava vinculada à idéia de desmitificar alguns dos pressupostos "evolucionistas" e/ou "etnocêntricos" das teorias de "aculturação", tentando compreender "aos outros" a partir das categorias ana líticas "identidade étnica" (Barth, 1969) e "fricção interétnica" (Cardoso de Oliveira, 1962).

Essas questões foram sendo problematizadas no transcurso das discussões que mantivemos, entre 1987 e 1988, a respeito da "pluralidade cultural" e, entre outros aspetos, sobre o debate das "novas práticas de dominação" exercidas sobre os "grupos étnicos" pelos denominados "Estados-Nação" surgidos do processo de independência dos territórios anteriormente controlados pelas metrópoles européias. Muitas das discussões foram desenvolvidas em algumas das disciplinas cursadas nos dois últimos anos da minha formação acadêmica (19871988) no Departamento de Antropologia Cultural da Universidade de Barcelona, e com antropólogos que participavam do coletivo denominado Estudis sobre o Tercer Mon (Estudos sobre o Terceiro Mundo) e da Oficina de Suport al Moviment Indi (Oficina de Apoio ao Movimento Índio), ambos com sede na cidade de Barcelona.

Em março de 1989, com nossos próprios recursos econômicos, chegamos a Belém; três pesquisadoras dispostas a realizar nossa primeira experiência de trabalho de campo. No mês de abril conseguimos realizar a primeira visita a uma aldeia Tembé da área do Guamá. Renato Trevisam, então coordenador do Conselho Indigenista Missionário (CIMINorte-II/Pará/Amapá), foi o mediador na negociação com a FUNAI para que pudéssemos obter a autorização de ingresso na Reserva indígena. A autorização foi concedida somente por três dias, sendo que fomos advertidas pelo Superintendente da FUNAI em Belém, Dinarte Madeiro, da impossibilidade de realizar outras viagens à RIARG sem a autorização jurídico-formal da sede do órgão indigenista em Brasília.

A finalidade principal dessa primeira viagem era, além, é claro, de estabelecer contato com os Tembé, tentar conseguir sua permissão para poder realizar futuras viagens às aldeias sem ter que esperar a autorização da FUNAI de Brasília. Em setembro de 1990, vinculadas formalmente ao Museu Paraense Emílio Goeldi, conseguimos, finalmente, que o órgão indigenista autorizasse nosso ingresso na RIARG para fazer a pesquisa. 
O início da nossa relação com os Tembé foi mediatizada, em parte, pelos critérios culturais das representações que alguns Tembé atribuíam aos agentes do $\mathrm{CIMI}^{6}$, entre os quais destacamos a noção de "ajuda": "O CIMI sempre ajudou a gente". Embora tenhamos sido classificadas como "as espanholas" que desejam conhecer "o tempo dos antigos" (nesta representação também estava implícita a categoria "ajuda" vinculada à relação anterior dos Tembé com um "médico espanhol"), a associação com as práticas de "ajuda" do CIMI foi uma marca que perdurou durante muito tempo na nossa relação com determinados membros do grupo, contribuindo, assim, segundo famílias e aldeias Tembé, para dar legitimidade ou não a nossa relação e adscrição ao grupo.

O controle exercido pelos agentes da FUNAI das entradas e saídas da Reserva, e o jogo de relações criadas no "campo de ação indigenista", desde o primeiro contato com os Tembé, contribuíram para forjar limites sociais à relação pesquisador-pesquisado e converteram-se num obstáculo para o desenvolvimento da pesquisa. Enquanto esperávamos a resposta da FUNAI, a estratégia que adotamos durante cerca de um ano para conseguir visitar algumas aldeias da Reserva através da mediação do CIMI influiu para que a nossa relação com os Tembé ficasse restrita às famílias de São Pedro e Tauari, aldeias nas quais o CIMI tinha maior aceitação, e também para que "ocultássemos" os motivos das viagens a essas aldeias. Deixamos, desta maneira, margem para criar diversas interpretações a nosso respeito, as quais pareciam se consolidar, não somente quanto à nossa relação com o CIMI, senão também com outras entidades nacionais ou internacionais responsáveis por "ajudar os pobres".

Essa estratégia também condicionou nossa relação com membros do grupo com os quais o CIMI tinha menos relação e/ou menor aceitação

6 Na viagem de abril de 1989 fomos acompanhadas por uma agente do CIMI, Raimunda de Oliveira Soares, conhecida pelos Tembé por Raimundinha, hoje coordenadora do CIMI Norte II. Nessa viagem limitamo-nos a seguir o ritmo de Raimundinha nas suas visitas às diferentes famílias que moravam na aldeia Tauari, nas quais sempre nos apresentava como "espanholas que vieram conhecer a vida do grupo". No decorrer do nosso trabalho mantivemos sempre relações de proximidade ou de amizade com outros agentes do CIMI na área. 
das práticas dos seus agentes, especialmente entre as famílias da aldeia do Posto, onde estava centralizada a administração da FUNAI na área da Reserva.

No início dos anos 80, a atuação dos agentes do CIMI na Reserva gerou situações de disputa entre diferentes atores no "campo de ação indigenista", as quais pressupunham, pensamos, diferentes significados para os mesmos. Por exemplo, os agentes da FUNAI se referiam a sua tentativa de dar "continuidade" às relações que os Tembé mantinham com eles como "índios tutelados". Por outro lado, para os agentes do CIMI essas situações de disputa expressavam a tentativa de diminuir o controle e monopólio que a FUNAI exercia na Reserva, pondo em prática estratégias destinadas à captação de membros do grupo (especialmente os das aldeias de São Pedro e Tauari), facilitando condições sociais que possibilitassem aos agentes missionários, por exemplo, um maior controle das relações sociais e sua legitimidade entre o grupo, como a constituição de "representantes" ou de "lideranças".

O elemento significativo da atuação dos agentes do CIMI não foi tanto a crítica da ação indigenista oficial, senão sua tentativa de mudar as relações de força a partir de uma ação político-religiosa fundamentada nas idéias que os agentes do CIMI tinham a respeito do grupo, segundo Padre Nello Rufaldi (Belém, 1990): “Os Tembé do Guamá não têm união (...), faltam lideranças (...), há muita mestiçagem, (...), situação de abandono muito grande (...), de muita necessidade, de submissão à FUNAI". Pretendia que a situação fosse revertida a partir do momento em que se "reavivasse um pouco a consciência de raça, de cultura, de povo (...), de ser Povo, ser Comunidade”. Os seus primeiros contatos com os Tembé devem ser contextualizados, pensamos, dentro desse processo de créditos e descréditos ou tentativa de legitimação dos diferentes agentes e das suas práticas, das quais parecia que eu também começava a formar parte.

\subsection{A condição de pesquisadora}

Desde minha primeira viagem aos Tembé do Guamá (abr. 1989), mantive uma relação mais ou menos direta ou sistemática com o grupo até dezembro de 1991. A minha localização ambígua dentro do grupo gerava, às vezes, situações potencialmente abertas para que os 
diversos agentes (Tembé, CIMI, FUNAI, a "antropóloga" Noêmia Pires de Sales`) me vissem, segundo contextos e situações específicos, como uma possível candidata favorável às suas expectativas de legitimação, como uma possível "aliada" ou "inimiga" - por mais que para mim a relação com os Tembé e os outros agentes não fosse então percebida como ambígua ou contraditória, pois a mesma, especialmente após a autorização da pesquisa pela FUNAI, foi explicitada publicamente para fins de pesquisa sobre a "história e vida do grupo".

No decorrer da relação com os Tembé, alguns membros do grupo, principalmente as "novas lideranças", atribuíram a mim condição de "pesquisadora" desvinculada do CIMI e passaram a solicitar minha colaboração na procura de informações sobre os "problemas da terra" - aspetos relacionados ao processo de regulação fundiária da RIARG - e, entre outras questões, a respeito dos "invasores" (classificação que unifica as categorias "madeireiros", "fazendeiros", "posseiros"; hoje também definidos pelos Tembé como "sem terra"). As demandas também faziam referência às práticas de socialização ou de "ajuda" na defesa e conquistas dos direitos por parte dos agentes do CIMI com alguns membros do grupo. Durante o trabalho de campo nas aldeias Tembé do Guamá, às vezes os membros do grupo requeriam minha "ajuda" para documentar alguns dos aspetos relativos às reclamações feitas por eles na Justiça, assim como para thes orientar na elaboração de documentos a serem encaminhados ao Poder Judiciário.

Entre 1990 e 1991, eu e minha companheira de pesquisa, Mercedes Zegrí, acompanhamos as "lideranças" Tembé nas reuniões realizadas em Belém, destinadas a discutir alternativas para acelerar a expulsão

7 No ano de 1982, Noêmia Pires de Sales desempenhou, como agente do CIMI, o trabalho de professora nas aldeias Tembé do Guamá, permanecendo vinculada à pastoral indigenista até finais de 1988. Em 1992, após concluir o curso de Especialização em Antropologia pela UFPa, Noêmia, iniciou um trabalho de pesquisa antropológica com os Tembé de Guamá financiada pela Universidade da Amazônia (UNAMA), à qual também estava vinculada como professora de Antropologia. Desde então, sempre manteve contato direto com os Tembé, desempenhando diversas práticas nas aldeias, como por exemplo "assessorar" nos trabalhos da constituição da Associação do Grupo Indígena Tembé do Guamá (Agitargma).

8 O termo aliado(a) foi incorporado nos últimos anos, principalmente nas representações das "lideranças", para definir as pessoas ou entidades governamentais ou não governamentais que "trabalham em favor da causa indígena". 
dos "invasores" da Reserva - realizadas na Sociedade Paraense de Defesa dos Direitos Humanos (SPDH), na ADR/FUNAI em Belém e no Ministério Publico. Destas reuniões também participavam "lideranças" Tembé do Gurupi, Kaapor e Timbira. Em várias ocasiões “a casa das espanholas" - assim estas lideranças denominavam a nossa residência em Belém - tornou-se um espaço de reunião dos representantes indígenas para discutir questões jurídicas referentes à regularização fundiária.

Essas demandas e atividades de "ajuda" contribuíram para consolidar a representação "de pessoa que estava disposta a ajudar", e para forjar critérios culturais de definição da categoria ajuda referentes à minha localização no grupo como pesquisadora, atribuindo-me certa legitimidade sobre determinadas "questões", como por exemplo a respeito do meu suposto "conhecimento dos direitos dos índios" e "do mundo de fora". Estas condições ampliaram meu "capital simbólico" entre os Tembé, que acredito importante contextualizar na atuação dos outros atores que formam parte do mesmo campo, além de contribuir para estimular e consolidar, de maneira geral, as expectativas dos Tembé depositadas na relação com a pesquisadora - particularmente as expectativas das "lideranças", cujo "capital social" e "interesse" como "pessoas de frente", ou como "pessoas que sabem lidar com o mundo dos brancos", estão estreitamente vinculadas à rede de relações que criam com as "pessoas de fora".

As "novas" diretrizes da política indigenista a partir do anos 90, com implicações diferentes no exercício da tutela, e, particularmente, as mudanças na ADR/FUNAI em Belém, são diferentes aspetos que favoreceram tanto as "novas" estratégias do CIMI na área, quanto as dos agentes da FUNAI, sendo criadas alianças ou uma "política de nova vizinhança" entre as duas agências de mediação. De acordo com um agente da ADR/FUNAI em Belém, à época advogado e responsável pelo setor Fundiário dessa administração:

9 A representação "pessoas de frente" refere a uma das qualidades ou atributos culturais de definição da categoria "liderança". A objetivação dessa representação pelos Tembé está vinculada, sobretudo, às práticas desenvolvidas pelos agentes da ADR/FUNAl em Belém a partir dos anos 90. 
"Há um tempo atrás havia um choque entre a política desenvolvida pelo CIMI e a FUNAI. Ultimamente não existe esse choque, porque a finalidade de ambos é melhorar as condições de vida do índio e proteger ao índio" (Amauri da Mota Azevedo, Belém, 1991).

Nesse novo contexto de "aliança" entre o CIMI e a FUNAI foram realizadas diversas reuniões na sede do CIMI (Belém), com a finalidade de procurar soluções conjuntas ao "problema Tembé"10. Fomos convidadas para participar dessas reuniões "as antropólogas" Noêmia Pires de Sales, Mercedes Zegrí e eu. Para os agentes do CIMI, da FUNAI e Noêmia, a minha condição de pesquisadora do grupo e antropóloga pressuponha a "obrigação de ajudar" os Tembé, entendida como uma retribuição dos meus conhecimentos. Como se tratasse de uma ordem natural, o antropólogo (neste caso eu) deveria também contribuir para a "conquista dos direitos dos índios" ou "ajudá-los nas suas necessidades". Ou seja, como se a atribuição de antropóloga tivesse implícita o "dever moral" do pesquisador que, atribuído de modo geral pelos seus conhecimentos e, particularmente, pela produção de conhecimento sobre o grupo, se fundamentasse na idéia de que o trabalho do antropólogo não só deveria beneficiar a si, mas também ao seu "objeto de estudo", sobretudo quando o mesmo é reconhecido socialmente como um "problema social". As palavras do chefe do Posto Indígena Canindé, Chico Potiguara, podem ajudar a exemplificar tais argumentações:

"Os grupos indígenas, eles são pessoas que vivem uma situação tão difícil do ponto de vista do despertar de tantos interesses e cobiça pelas suas terras, (...) que eles têm tantos inimigos, tantas pessoas que querem destruir o índio. Porque a opinião majoritária é que o índio é um estorvo e um empecilho, deve sumir, deve se agregar porque [o índio] é

10 A caracterização da coletividade Tembé como um "problema" está vinculada as condições que levam a determinados agentes do campo de ação indigenista a sentir a necessidade ou "dever moral" de "ajudar" aos Tembé, por ser considerado como grupo "descaracterizado culturalmente", "miscigenado", com "conflitos entre seus membros", contribuindo, pela falta de 'consciência' que têm do seus direitos, para a acentuação dos "problemas da terra". 
coisa de primitivo atrasado e ele tem que deixar de ser daquela maneira. Então eu acho que se você tem uma formação, teve a oportunidade de ter uma formação de estudo, eu acho que tem a obrigação de tentar usar o seu saber, seu conhecimento no sentido de defender aquele grupo (...), através de seu trabalho, através da sua capacidade de mudança, aqui na nossa sociedade, para que defenda os interesses daqueles índios (Chico Potiguara, Belém, 1998) ${ }^{11}$.

Ainda que as interpretações de Chico Potiguara devam ser vinculadas às condições em que são produzidas, e/ou à posição que Chico ocupa dentro do "campo de ação indigenista" como funcionário da FUNAI, destinado a exercer as funções de "chefe de posto" ou "técnico indigenista", elas nos permitem não somente sintetizar as palavras dos outros agentes que formam parte constitutiva do mesmo campo de ação indigenista (leia-se, por exemplo, os membros do CIMI), mas também revelar a base ética e/ou cultural na qual se fundamentam as idéias que estruturam as representações e práticas desses agentes. Isto é, o babitus ${ }^{12}$ desse campo, cujo código ético se rege segundo a lógica da "generosidade" ou do "desinteresse", ou melhor, no "dever moral" de "ajudar os "grupos indígenas", no caso, “ajudar os Tembé na solução dos seus problemas".

11 Chico Potiguara, após ser aprovado em concurso e realizar um "curso indigenista", ingressa na FUNAl em 1985. Potiguara tem uma formação, segundo suas palavras, "humanista", que procede da sua "militância em partido comunista e envolvimento em movimento estudantil na Universidade". Embora sua preocupação com os índios não esteja diretamente relacionada à formação de militante de esquerda, Potiguara considera que o caráter humanista procedente dessa trajetória militante, preocupado com as minorias, contribuiu para que ele tivesse, após sua experiência como chefe de posto das áreas indígenas, uma maior sensibilidade pela "causa indígena" (Chico Potiguara, Belém, 1998).

12 Tomamos a noção de habitus no sentido elaborado por Bourdieu: é importante pensar em termos de habitus e de campo porque "permite compreender que existem comportamentos desinteressados que não têm como princípio o cálculo do desinteresse, a intenção calculada de superar o cálculo ou de mostrar que se é capaz de o superar. (...) Se o desinteresse é possível sociologicamente, é porque existe uma coincidência entre uns habitus predispostos ao desinteresse e uns universos nos quais o desinteresse está recompensado" (Bourdieu, 1994, p. 153-5). 


\section{As situações de "ruptura" e manifestação das "obrigações" de "ajuda" do pesquisador}

Ao concluir formalmente, em 1991, a pesquisa sobre "contatos interétnicos", optei por dar continuidade à minha formação de antropóloga iniciando um curso de mestrado no Museu Nacional (UFRJ). Em setembro de 1992, ao retornar a Belém durante minhas férias, fui procurada por uma das "lideranças" Tembé do Guamá, que me informou das novas normas aprovadas pelo grupo durante a minha ausência e das "obrigações" de eu teria que cumprir para prosseguir o trabalho de campo nas aldeias. Duas normas me foram impostas: viajar à área com o prévio aviso pelo sistema de fonia da ADR/FUNAI em Belém e a "obrigação" de realizar uma viagem às aldeias do Guamá para mostrar os resultados da pesquisa e para lhes entregar cópia do trabalho. Também me foi solicitado que explicasse quais eram os meus projetos futuros como antropóloga.

Um mês depois viajei à área de Guamá. Cumprindo as normas, entrei na reserva pela aldeia do P.I. Guamá. Ao chegar à aldeia São Pedro, realizou-se uma assembléia na qual fui informada que as exigências para entrar na área respondiam à necessidade do controle de entradas e saídas da Reserva para evitar riscos sobre possíveis divulgações das discussões e daquilo que acontecia nas aldeias. A outra exigência estava relacionada com o trabalho de pesquisa e com a minha nova localização como antropóloga, defendida nos termos de contribuição ao conhecimento da história do grupo. Informei dos resultados da pesquisa, correspondente ao período 1989-1991, e entreguei-lhes uma cópia do trabalho titulado Los Tembé: Articulación Interétnica e Identidad Étnica, informando-lhes também de minhas intenções de regressar novamente a Rio de Janeiro para prosseguir com meus estudos, dos quais dependia também a possibilidade de voltar ao Estado de Pará, a fim de dar continuidade à minha pesquisa.

As "obrigações" que me foram impostas em outubro de 1992, como condições feitas públicas pelo grupo, revelavam uma "ruptura" na minha relação com o grupo, que implicou em uma continuidade e descontinuidade no marco das prestações e contraprestações da relação entre pesquisador-pesquisado. Até esse momento, as petições de "ajuda" feitas pelos Tembé nunca me haviam sido colocadas como uma 
condição prévia para que eles aceitassem minha presença na Reserva, ou para poder desenvolver a pesquisa, como se as minhas viagens à RIARG e o próprio tempo de permanência nas aldeias respondessem apenas ao meu cronograma de trabalho e à dinâmica da interação com o grupo. A única imposição formal para poder realizar a pesquisa era a de obter (e manter) a autorização concedida pela $\mathrm{FUNAI}^{13}$, aparentemente desvinculada da relação que mantinha com o grupo, não existindo em nenhum momento, por parte dos Tembé, imposições prévias.

A paralisação da pesquisa com os Tembé após março de 1992 foi vivenciada por alguns membros do grupo como não-cumprimento das minhas "obrigações". Fui recriminada por ter ido "embora e não falou nada para a gente (...), assim não dá, porque a comunidade tem que saber o que a pessoa veio fazer aquil” (Kelé, aldeia São Pedro, 1992). Ao contrargumentar que essas acusações eram infundadas, pois eu tinha informado ao grupo, em fins de 1991, dos meus planos de morar no Rio de Janeiro, o próprio Kelé, na época "Cacique Geral” dos Tembé do Guamá, argumentou:

"Tudo bom, nesse tempo as coisas eram diferentes, o pessoal entrava, ia embora e ninguém sabia nada do que acontecia. Agora não, agora qualquer pessoa de fora que chegar na área tem que falar com a 'comunidade' e dizer o que veio fazer. É assim que foi colocado no "regime".

Foi nesse momento que, pela primeira vez, fui classificada como "antropóloga" e como "pessoa de fora" a quem se atribuía uma série de normas e/ou obrigações, entre elas, minha contribuição como pesquisadora e a obrigação de informar minhas entradas e saídas da reserva.

Contextualizadas tais "obrigações" dentro das "novas" condições sociais, geradas a partir de abril de 1992, coincidiram com a chegada à

13 Esta autorização oficial para poder realizar pesquisa na Reserva está relacionada ao procedimento legal da FUNAl sobre a produção de conhecimento a respeito dos "grupos indígenas" que estão sob sua tutela. Ver Oliveira Filho, s.d.

14 A designação de Dilson como "chefe de posto" vincula-se com as preocupações do administrador da FUNAI de Belém, Frederico Miranda, em conseguir agentes de acordo com os "valores indigenistas" (leia-se "ideal humanista Rondoniano"), contextualizado dentro da "nova linha" da administração de Belém, implementada por Miranda entre 1991 e 1996. Em junho de 1997, Dílson foi novamente nomeado para o mesmo cargo, no qual permanece até hoje. 
área de Guamá de um novo chefe de posto, Dilson Marinho ${ }^{14}$. Este processo, denominado pelos Tembé de "Reorganização-Revolução" influiu, entre outros aspetos, para a "invenção" de práticas rituais ou simbólicas e de novas formas de controle e regulação social do grupo, em estreita conexão com a idéia manifesta por alguns Tembé de mudar, enquanto grupo "autenticamente Tembé”"15, sua condição de "índios tutelados", visando a "defesa e garantia dos seus direitos sobre o território” (Alonso, 1996). Num sentido mais amplo, essa novas condições devem ser vinculadas à luta pela institucionalização e legitimação social dos Tembé, processo que, em 1996, teve sua expressão jurídica com a constituição da Associação do Grupo Indígena Tembé do Alto Rio Guamá (Alonso, 1999).

\subsection{Os referenciais de antropólogo e os critérios atribuídos à categoria antropólogo.}

A atuação do "chefe de posto" Dilson Marinho e a presença da antropóloga Noêmia Pires de Sales (que estava realizando, nesse período, sua investigação com o grupo) foram dois elementos relevantes para a minha localização no grupo como antropóloga e para a "imposição" das "obrigações" relativas a essa classificação, colocadas, sobretudo, pelas lideranças. Por exemplo, durante a viagem de 1992 uma das lideranças comentou comigo: "Porque vocês (referindo-se a mim e à Noêmia) são antropólogas, né? (...), e poderiam ensinar para a gente muita coisa da cultura dos antigos" (Cambeua, aldeia P.I. Guamá, out/1992).

Nessa mesma viagem defrontei-me com varias situações nas quais também o novo "chefe de posto", classificando-me como antropóloga, argumentava a "necessidade" da minha contribuição ao grupo, tanto pelos meus contatos no exterior, aparentemente favorecidos pela minha "nacionalidade estrangeira", como também pelo meu conhecimento "sobre" o grupo, ou pelo meu "saber" como antropóloga, que supostamente me autorizavam a produzir conhecimento e/ou falar sobre a "vida e cultura dos índios".

15 O conceito "autenticamente Tembé" foi usado na minha dissertação de mestrado com o intuito de compreender os critérios de legitimidade de grupo e/ou da cultura e identidade Tembé a partir de uma proposta de desnaturalização ou desubstancialização dos mesmos (Alonso, 1996). 
Além dos seus pressupostos a respeito do "saber antropológico" (leia-se sobre os "índios do Brasil"), Dilson tinha como referencial do que é - ou deve ser - um "verdadeiro antropólogo": Dominique Gallois. Segundo Dilson, "Dominique estudou muito a cultura dos Waiãpi e conhece muito bem seus costumes, tradições. Ela não é do tipo de antropólogo que vai lá, estuda os índios e depois vai embora e não lembra mais (...), faz muita coisa pelos índios Waiãpi, além do mais é uma pessoa muito conhecida, tem muitos contatos não só aqui no Brasil, lá fora também, faz projeto ela consegue recursos. Tudo isso é muito bom para os índios"16.

Para alguns Tembé os referenciais "legítimos" da categoria antropólogo eram Dominique Gallois, Lúcia Andrade e principalmente o trabalho desenvolvido na RIARG por Noêmia Pires de Sales. Gallois é conhecida como a "antropóloga dos índios Waiãpi”, atributo que está vinculado às práticas do chefe de posto do P.I. Guamá, Dilson Marinho. As representações a respeito de Andrade eram mais genéricas, sendo vinculadas ao seu "trabalho político" como "assessora dos índios Tupi”" Em relação à antropóloga Noêmia Sales, além do trabalho de pesquisa, destaco sua atuação como "assessora profissional", como ela faz questão de definir sua prática política vinculada à categoria de antropóloga. Nesta categoria se inclui sua atividade como pesquisadora e contribuição na produção de conhecimento sobre a "história dos Tembé", recopilando, por exemplo, material historiográfico a respeito das "origens", "migração" e "localização espacial” do "grupo TembéTenetehara" e "cultura dos antepassados"18, e seu trabalho como assessora na criação, em 1996, da Associação dos Tembé do Guamá.

\subsection{As lutas de classificação na relação pesquisador-pesquisado}

Em setembro de 1995, ao retornar ao Estado de Pará com a finalidade de concluir o trabalho de campo para a dissertação de mestrado,

16 Entre 1988 e 1991, Dilson Marinho exerceu o cargo de chefe substituto da FUNAl com os índios Waiãpi (Estado do Amapá).

17 Lúcia Andrade participou como antropóloga e membro da Comissão Pró-Índio de São Paulo na criação e assessoria do Conselho de Articulação dos Povos Tupi (ANTAPAMA), entidade criada formalmente em 1992.

18 O conceito Tenetehara é usado na literatura antropológica para definir os grupos Tembé e Guajajara a partir da classificação "Tupí-Tenetehara", fundamentada na 
informei aos Tembé do Guamá e de Gurupi através da fonia da FUNAI em Belém sobre a minha intenção de viajar às aldeias. Sem esperar sua resposta, viajei à área de Guamá em outubro. Aquela atitude estava fundamentada nas supostas intenções de retorno "criadas" na minha última viagem realizada em 1992, consciente de que estava "infringindo" a norma de obter a prévia autorização da "comunidade" para entrar na Reserva enquanto "pessoa de fora" e a de informar os motivos da minha viagem. Foram realizadas reuniões em três aldeias, com a finalidade de negociar a realização da investigação nos termos acordados em 1992 e de informar sobre a minha vontade de pesquisar a respeito da "sua cultura", além da proposta de incluir também na pesquisa os Tembé do Gurupi ${ }^{19}$. Surgiram discussões em torno de como fazer a pesquisa, ou dos procedimentos a seguir na elaboração do texto. Alguns Tembé mostraram seu interesse e preocupação em discutir os resultados da pesquisa antes de eu apresentar o texto ao Museu Nacional, assim como também a respeito dos Tembé que deveria escolher como "informantes".

Esta preocupação com a forma final do texto e a escolha de "informantes autorizados" pelos Tembé está estreitamente relacionada com os efeitos sobre o grupo das "lutas de identidade" ou da definição "verdadeira” de ser índio Tembé. Em várias situações, o grupo tem sido colocado em questão, sendo caracterizado segundo os estereótipos que definem a coletividade denominada "população regional" (leia-se nacional na sua dimensão regional), mais do que propriamente como "índios"

Tanto nos momentos da negociação como no decorrer da pesquisa, foram vários os contextos em que os Tembé faziam referências explícitas às interpretações que alguns pesquisadores e/ou antropólogos tinham feito sobre o grupo, fossem elas para questionar ou para confirmar a identidade Tembé. A esse respeito, uma liderança do Guamá argumentou:

definição de "áreas culturais" em base a critérios lingüísticos e culturais, utilizada entre outros, pelos "teóricos da aculturação".

19 A respeito da relação pesquisador pesquisado com os Tembé do Gurupi, ver Alonso, 1999, especialmente os capítulos II, IV e V.

20 Uma análise do processo da "luta de identidade Tembé" como um tipo de "luta de classificação" foi abordado na sua positividade na dissertação de mestrado e nos desdobramentos posteriores da mesma, que resultaram na produção de dos artigos, intitulados: "A Disputa pelo Sangue: Reflexões sobre a Constituição da Identidade e Unidade Tembé" (Alonso, 1997) e "A Identidade e a Memória como Fenômeno de Construção Social: os Tembé e o 'Tempo dos Antigos'"' (Alonso, 1998). 
"Porque já veio antropóloga por aqui que nos prejudicou falando muita mentira, que nós não era índio, que era tudo misturado. Ela ia perguntando a todo mundo se era índio ou misturado. Aí depois colocou no papel, no documento dela, e pronto, ninguém podia fazer nada. Por isso, que nós quer saber, antes de tu entregar para o teu chefe, lá no Rio, nós quer saber o que tu vai escrever no teu documento sobre o povo Tembé. Tu não vai falar da gente? Falar de nós? Então nos precisa saber se é certo ou errado o que tu vai contar no papel" (Piná Tembé, P. I. Tembé, 1995) ${ }^{21}$.

Nessas interpretações de Piná, cabe sublinhar também a maior eficácia performativa que a escrita tem sobre a "realidade social", ou para a demonstração das "verdades". O caráter fixo e formal que a escrita fomenta parece ser uma das preocupações que se desprendem das suas interpretações.

Para complementar estas argumentações, considero de interesse mencionar os pressupostos de "autenticidade cultural" e de "unidade social" com os quais trabalhamos, eu e a minha companheira de pesquisa, Mercedes, nos primeiros anos da pesquisa - os quais dificultaram, na época, a compreensão do fenômeno a ser analisado. Mostra disso foram as discussões que mantivemos durante esse período a respeito de se os Tembé do Guamá eram ou não um grupo indígena reflexões que se fundamentavam na própria experiência de campo ao nos defrontarmos durante os primeiros meses de pesquisa com o mesmo questionamento vindo de alguns membros do grupo. Foram criadas diversas situações de crise, nas quais diferentes membros do grupo questionavam uns aos outros sobre os limites e sentimentos de pertença, ou sobre quem tinha ou não "sangue índio".

Nas reuniões que realizei durante esses primeiros contatos com os membros do grupo para lhes expor os objetivos da pesquisa (19891990), um dos aspectos levantados por alguns Tembé fazia referência à noção de identidade étnica ou à definição da identidade em termos de auto-atribuição e atribuição pelos outros. Por exemplo, perguntas direcionadas a obter de mim uma opinião ou explicação sobre suas

21 Piná é representante dos Tembé no Conselho da organização ANTAPAMA, onde exerce o cargo de Coordenador Geral. 
idéias a respeito do "fato" deles se considerarem índios, mas que o pessoal de fora não os considerava assim, ou seja, sobre idéias ou noções tais como "misturados" ou "desaculturados".

Com a intenção de responder às suas perguntas e dúvidas a respeito das diversas situações de ambigüidade de sentimentos de pertença, minhas respostas foram orientadas a valorizar a definição de autoatribuição e sublinhar a necessidade de parar com as disputas entre si para chegarem a uma solução ou acordo conjunto. Isto é, mostrar a idéia de que só eles podiam definir se eram ou não índios e definir seu significado como grupo.

Como já assinalei, a pretensão de alguns Tembé de me classificar como a "nossa antropóloga" foi outro dos elementos incorporados nas negociações de 1995. Eu estava consciente de que a não aceitação dessa classificação poderia pôr em questão meu "contrato" com os Tembé ou, pelo menos, fazer com que alguns membros do grupo pensassem que eu poderia deixar de cumprir no futuro as "obrigações" ali definidas. Entretanto, a não aceitação dessa classificação influenciou para que nas reuniões aparecesse, explicitamente, outra série de argumentos a respeito dos critérios que alguns Tembé atribuíam à categoria "antropólogo", como, por exemplo, a legitimidade dos antropólogos como "porta-vozes" dos direitos dos índios: "O antropólogo é uma pessoa importante que fala e briga com o governo para defender os direitos dos índios" (Israel, Aldeia São Pedro, 1995).

Embora correndo os riscos de não obter a autorização e/ou de provocar uma ruptura na relação pesquisador-pesquisado, rejeitei algumas das condições que, sobretudo, as lideranças pretendiam me impor, entre elas a escolha dos informantes e o processo de discussão a respeito do texto antes da defesa no Museu Nacional, argumentando a incompatibilidade de aceitá-las para o bom desempenho do meu trabalho. O resultado final da negociação foi a permissão para desenvolver o trabalho de pesquisa segundo os meus critérios, mas com o compromisso assumido por mim publicamente nessas reuniões de que após a defesa da dissertação, além de discutir com o grupo os resultados da pesquisa, eu teria a "obrigação" de retribuir ao grupo - isto é: assessorar o grupo a respeito dos "problemas da nossa terra" e na elaboração e viabilização de projetos destinados a resolver outros "problemas" como "educação", "saúde" e "lavoura". 
Essas "negociações" e seus resultados devem ser relacionados com a minha condição de pesquisadora e estudante vinculada a uma instituição oficial (Museu Nacional/UFRJ) que, para os Tembé, pressuponha que a conclusão do meu trabalho sobre o grupo iria "ajudar" na minha profissão. Além disso, essas "negociações” devem ser relacionadas com o processo que algumas lideranças Tembé denominam "o nosso regime", com a intenção de se opor à ordem criada durante o processo denominado de "Reorganização-Revolução", em que essas lideranças pretendiam então deslegitimar o "anterior regime” argumentando que fora criado ou imposto, em 1992, pelo então chefe de posto Dilson Marinho, e não pela "comunidade", pelo "nosso povo".

Em relação à categoria antropólogo, considero pertinente destacar também o vínculo que existe entre os critérios que "os Tembé" atribuem a essa classificação e aqueles que são atribuídos ao antropólogo dentro da divisão que se faz do trabalho no "campo intelectual". É possível afirmar que o "senso comum acadêmico" teve efeito mágico sobre a "realidade social brasileira", como revelam as práticas e representações que os Tembé elaboram sobre o "antropólogo legítimo". Não obstante, para evitar cair em naturalizações ou determinismos culturais, é necessário questionar tais representações, tidas como dadas, e considerá-las no contexto no qual se atualizam ou realizam.

Se, por um lado, os Tembé atribuíam, de maneira geral, critérios de definição legítima à categoria antropólogo tomando como base os critérios do senso comum acadêmico, por outro, tais atribuições pressupunham, para alguns Tembé, questionar a legitimidade desses critérios, particularizando e/ou criando nos diversos contextos suas atribuições culturais como, por exemplo, através da representação "nossa antropóloga". Pois, ainda que exista na "realidade" uma certa definição "oficial” da categoria antropólogo, penso que é nos contextos de interação que ela se faz e se realiza. Em outros termos, não se trata da representação antropólogo com categoria "dada" ou "objetiva" que define os critérios culturais do "antropólogo(a)", porém o antropólogo que o grupo reconhece e acredita e, portanto, atribui-lhe ou não autoridade e legitimidade as suas ações.

Na mesma linha de argumentação é possível tentar compreender as preocupações de alguns Tembé a respeito da elaboração e redação final do meu texto, cuja negociação permitiu não apenas esclarecer melhor os 
critérios da categoria antropólogo, mas também revelar, parafraseando Bourdieu, uma característica constitutiva das lutas de classificação, colocando em jogo, ao mesmo tempo, a definição das atribuições do antropólogo, a identidade social do pesquisado e pesquisador, e as várias expectativas de cada um destes atores nas relações entre pesquisador e pesquisado(s), ou entre "sujeito conhecedor" e o "sujeito empírico".

\section{Considerações finais}

No decorrer das observações feitas durante este trabalho, tentei compreender a representação "a Sara vai ajudar a gente" como uma das principais interpretações realizadas pela maioria dos membros dos grupos sobre a minha presença nas aldeias, além das obrigações decorrentes da relação de amizade e/ou de proximidade entre membros dos grupos e a pesquisadora. Esta interpretação deve ser compreendida dentro do contexto mais geral da "obrigação de ajudar" de qualquer pesquisador que deseja permanecer nas aldeias para desenvolver seu trabalho.

Foi durante a viagem de 1992 que os "desejos" implícitos do pesquisado frente ao pesquisador, assim como os deste frente ao grupo foram objetivados publicamente, revelando a eficácia das "trocas" nessa relação, ao unir ambos através de vínculos de "dependência", vínculos que "obrigam" o pesquisador e o pesquisado a resolver os "conflitos", negociando as condições futuras de legitimidade da relação. As "negociações" estabelecidas em 1995 entre pesquisador-pesquisado foram percebidas como uma "continuidade" do contexto de ruptura negociado durante a experiência de 1992, vinculado às práticas do administrador de Belém, a partir de elementos, significações e/ ou interesses mais formalizados. Efeitos de "formalização" ou de "normalização", contextualizados no processo da luta pela institucionalização e legitimação dos grupos, tiveram com a criação da Associação dos Tembé de Guamá (AGITARGMA), em 1996, a manifestação "consagrada" desse processo.

As "obrigações" que me impuseram os Tembé em 1992 estavam vinculadas à classificação de antropóloga como atributo que define a legitimidade desta categoria de cientista social para produzir conhecimento sobre os índios e falar e defender seus direitos. Em 1995, momento da 
minha última viagem ao campo antes de concluir a dissertação de mestrado, as condições colocadas pelos Tembé nas negociações poderiam ser interpretadas como dom e contradom. Dom por sua "vontade" de favorecer o incremento do meu "capital simbólico" após a finalização da minha pesquisa, que deveria ser retribuído com o reconhecimento público do meu compromisso de "ajuda" ao grupo após meu retorno ao Estado do Pará; contradom, também entendido como uma arma nas negociações, de me negar a permissão para permanecer ou regressar às aldeias no caso de não aceitar suas condições, isto é, por não cumprir as "obrigações" que eles atribuem como legítimas aos antropólogos.

Considero como um importante desafio para as instituições científicas e seus pesquisadores que desenvolvem investigações na Amazônia avaliarem positivamente as propostas de apoio e/ou de "ajuda" aos grupos indígenas, concretamente, as que estão sendo encaminhadas pelas sociedades Tembé, Timbira e Kaapor, assim como tentar retribuir-lhes dentro das possibilidades de ação que competem a seu "campo político-científico", seja na área do conhecimento e saber, quanto na da sensibilidade e respeito.

Ainda que o pesquisador, consciente ou inconscientemente, tenha tentado ocultar esta relação entre "trabalho político" e "trabalho científico", priorizando, segundo o contexto, um em detrimento do outro, considero que os dois aspectos formam parte constitutiva da "experiência social" do cientista social no Brasil, particularmente na Amazônia, como produtor de conhecimento. Os efeitos deste conhecimento sobre a "realidade social", particularmente sobre aquela que os cientistas pesquisam, hoje se manifestam de maneiras diferentes às ocorridas em períodos anteriores.

O trabalho do pesquisador deve ser compreendido também como uma possível demanda do grupo que implica, segundo Bourdieu, em fazer uso da objetivação participante na elaboração e construção do objeto de pesquisa e no seu desenvolvimento. A tendência à formalização das relações entre os membros dos grupos e dentro de cada grupo, através das associações indígenas, está criando condições para uma relativa formalidade das relações entre pesquisador e pesquisado, "obrigando" o pesquisador a estabelecer vínculos de caráter aparentemente formais e/ou "racionais" que podem ocultar seus próprios interesses e valores morais implícitos nessa relação. Quer dizer, como se 
as "obrigações de ajuda" fossem não apenas decorrentes das exigências do grupo, mas parte e resultado constitutivo da própria experiência e trajetória social do pesquisador e/ou antropólogo.

\section{Referências bibliográficas}

ALONSO, Sara. "Os Tembé do Guamá: Processo de construção da cultura e identidade Tembé". Dissertação de Mestrado. PPGAS/MN/UFRJ, Rio de Janeiro, 1996.

. "A Identidade e a Memória como Fenômeno de Construção Social: os Tembé e o 'Tempo dos Antigos'". In: International Oral History Conference Proceedings. Rio de Janeiro, CPDOC, 1998. p. 618-28.

BARTH, Frederick (ed.). Ethnic Groups and Boundaries. London, George Allen \& Unwin, 1969.

CLIFFORD, James. "The Predicament of Culture: Twentieth-Century Etnography". In: Literature and Art. Cambridge, 1989.

Jucar, 1991.

\& MARCUS, George (orgs.). Retóricas de la Antropologia. Gijon,

BOURDIEU, Pierre. "L'action du temps". In: Le Sens Pratique. Paris, Ed. du Minuit, 1980.

. "A identidade e a representação. Elementos para uma reflexão crítica sobre a idéia de região". In: O Poder Simbólico. Lisboa, Difel, 1989. ma, 1994.

- Razones práticas; Sobre la Teoria de la acción. Barcelona, Anagra-

"Marginália. Algumas Notas Adicionais Sobre O Dom". In: Mana, Rio de Janeiro, v. 2, n. 2, 1996, p. 7-19.

BOURDIEU, Pierre \& WACQUANT, Loïc. Per uma Sociologia Reflexiva. Barcelona, Herder, 1994.

MAUSS, Marcel, "Ensaio sobre a Dádiva. Forma e Razão da Troca nas Sociedades Arcaicas". In: Sociologia e Antropologia. São Paulo, EPU, 1974.

OLIVEIRA FILHO, João Pacheco de. "Notas sobre a Normativização da Autorização de Pesquisa Etnológica". Mimeo, s/d.

O Nosso Governo. Os Ticuna e o Regime Tutelar. São Paulo, Marco Zero/MCT-CNPq, 1988.

OLIVEIRA, Roberto Cardoso de. Identidade, Etnia e Estrutura Social. São Paulo, Livraria Pioneira Editora, 1962. 
PETI. Terras Indígenas no Brasil. São Paulo, CEDI, 1990.

WEBER, Florence. Le Travail à coté: Etude d'Ethnographie ouvrière. Paris, Editions de la MSH, 1989.

Resumo: A partir da minha experiência de pesquisa com os Tembé de Guamá, grupo localizado na Reserva Indígena Alto Rio Guamá (Pará), pretendo abordar neste artigo alguns aspectos que subjazem à lógica da relação pesquisador-pesquisado, compreendida como uma relação social de longa duração, sustentada em critérios culturais para seu grau de controle e legitimidade. Também pretendo avaliar alguns dos efeitos performativos dos discursos dos cientistas sociais "sobre a realidade social Tembé", os quais, como agentes legítimos para produzir conhecimento, através de seus atos de fala ou de categorização, fazem "sobreviver o que ele enuncia no próprio ato de o enunciar".

Palavras-chave: Antropologia Social; Índios Brasil; Tembé; Cientistas Sociais; Relação Pesquisador-Pesquisado.

The Tembé and the Researcher-subject ReLATIONSHIP

ABSTRACT: Based on my research experience among the Tembé Indians of the Alto Rio Guamá Indian Reserve of Pará state, Brazil, this article addresses aspects of the relationship between researcher and subject. This tie implies a long-term social relationship based on cultural factors, which establish the degree and control of legitimation. I reflect also on the performative effects of this relationship, to the extent that the anthropologist's discourse bears upon "Tembé social reality". Thus, as the anthropologist is deemed as the bonafide agent in producing knowledge, his/her speech acts and/or categorization improve social legitimation, and are intended to "breathe life into utterances by the very act of uttering".

KeYwords: Social Anthropology; Brazil Indians; Tembé; Social Scientists; Relationship Researcher-Subject. 